\title{
A obra de Mario Quintana pode ser lida por crianças?
}

\section{Simone Assumpção*}

Resumo: O presente trabalho pretende discutir e definir critérios de seleção de textos poéticos para crianças e também discutir a idéia - aparentemente consensual - de que determinados livros de nosso poeta alegretense se dirigem ao leitor infantil. Nesse sentido, é preciso definir o que é Literatura Infantil se ela existe de fato - e é preciso também levantar hipóteses relativas à recepção das obras de Mario Quintana.

\begin{abstract}
Can the works of Mario Quintana be read by children? This text discusses and attempts to define criteria for the selection of poetic texts for children. It also discusses the apparently consensual idea that certain books written by Mario Quintana (a Brazilian poet, born in Alegrete) are meant for children. In this sense, we have to define what children's literature is - and if it indeed exists. We also have to raise hypotheses concerning the reception of Mario Quintana's works.
\end{abstract}

Palavras-chave: Mario Quintana; poesia infantil; literatura infantil.
Keywords: Mario Quintana; children poetry; children literature.

Ao questionar se a lírica de Quintana pode ser lida por crianças, o presente trabalho problematiza o que aparentemente transformou-se em senso comum. Várias obras de Mario Quintana apresentam, em suas capas, ilustrações que remetem o leitor à idéia de que se trata de literatura infantil quando, na verdade, os textos poéticos que as compõem mereceriam um pouco mais de reflexão antes de serem oferecidos ao leitor iniciante. Nesse sentido, a proposta é refletir sobre determinadas obras do poeta alegretense/porto-alegrense que poderiam ser atrativas para o leitor mirim.

Para delimitarmos nossa problemática, formulemos aqui algumas perguntas norteadoras que poderiam se aliar àquela do título: Quintana escreveu para crianças? O que é um livro para crianças? Quais são os critérios de seleção? A quem cabe estabelecê-los? Quais são os procedimentos para tal escolha?

\footnotetext{
* Simone Assumpção cursou a graduação em Letras pela Universidade Federal do Rio Grande do Sul (1989), mestrado em Letras e Lingüística pela Pontifícia Universidade Católica do Rio Grande do Sul (1993) e doutorado em Letras pela Pontifícia Universidade Católica do Rio Grande do Sul (2000). Atualmente é docente do Curso de Letras na Universidade do Vale do Rio dos Sinos. Tem experiência na área de Letras, com ênfase em Literatura Infanto-juvenil, atuando principalmente nas seguintes áreas/ temas: literatura infanto-juvenil, poesia e hipertexto, leitura, poesia infantil e comunidade virtual.
} 
Comecemos pela pergunta "Quintana escreveu para crianças?" Não estamos aqui nos referindo à intenção do autor. Em primeiro lugar, porque, se não houver documento onde tal intenção esteja expressa, não há como saber o que pensava Quintana a respeito. Em segundo lugar, entre a intenção - supondo-se a existência de tal documento - e o texto final, há uma longa distância. Muitas vezes, o autor define objetivos, mas seu trabalho, submetido ao crivo de outros olhos, revela que aqueles nem sempre são alcançados.

Contradizendo tal hipótese, em Sapato furado, livro publicado em 1994, Quintana manda um recadinho pros leitores a partir dos dez anos: "Eu já escrevi o Sapato florido. Como, porém, nesta vida nem tudo são flores, apresento-vos agora o Sapato furado, que tem grande significação, pois o seu texto foi escolhido exclusivamente pelos leitores a se destina: a gurizada a partir dos dez anos..." (QUINTANA, 2005, p. 974).

Explicitada a intenção do poeta, pensemos nos livros que geralmente são citados como infantis. Quais são eles? Na recentemente publicada Poesia completa, da editora Nova Aguilar, há uma parte intitulada "Poemas para a infância", na qual se encontram $O$ batalhão das letras, Lili inventa o mundo, Pé de pilão, Sapo amarelo e, finalmente, o já lembrado Sapato furado. Ora, o que faz com que essas obras encontrem-se no mesmo grupo e num grupo que tem como identidade o fato de serem livros para o público infantil?

Formulemos nova pergunta: o que é um livro de literatura para crianças? Resposta: é um livro que possa vir a ter algum elemento atrativo para aquele público. Uma pequena ressalva se faz aqui necessária: o quê interessa para uma criança de quatro anos não é o quê interessa a uma criança de onze e, ainda, o quê interessa a uma criança de onze anos em 1950 não é o mesmo que a uma criança da mesma faixa etária em 2006.

Voltemos, pois, ao Sapato furado. O primeiro poema traz como título "Conto azul". A dedicatória de Quintana nos leva a crer que o leitor de onze anos poderia ali encontrar significado(s), o que nos faz formular mais uma pergunta: o que esse leitor poderia fazer emergir de tal texto?

\section{CONTO AZUL}

Certa vez, tinha eu quinze anos, inventei uma história que principiava assim:

"A primeira coisa que fazem os defuntos, depois de enterrados, é abrirem novamente os olhos."

Mas fiquei tão horrorizado com essa espantosa revelação que não me animei a seguir avante e a história gorou no berço, isto é, no túmulo. (QUINTANA, 2005, p. 974)

Evidentemente, trata-se de uma temática instigante: a morte com todos os seus mistérios. Além disso, o tom jocoso e o tratamento lúdico do poema fazem-nos pensar em uma suposta simetria entre o autor e o leitor do texto. O poeta consegue aqui aproximar-se da leveza com a qual o jovem realiza sua existência, ao mesmo tempo em que provoca o 
ludismo com o trocadilho "gorou no berço/gorou no túmulo". Também a possibilidade de que os defuntos possam fazer algo depois de assumirem essa condição soa como algo leve, diferente do usual tratamento sério ou religioso dado ao tema. A idéia de "tudo azul", anunciada e antecipada pelo título, também nos faz pensar no jogo lúdico. A expressão "tudo azul" revela a idéia de que tudo está bem.

Feito este exercício pontual, pensemos na segunda pergunta, ampliando-a: o que é um livro de literatura para crianças? A professora e pensadora venezuelana Griselda Navas (2000, p.57) afirma que a "literatura para niños nos es jamás la que los escritores escriben, sino la que los niños al leer aceptam y hacen propia, la que eligen o preeligen”. Sendo assim, é preciso pensar a partir da ótica de um hipotético leitor. Alguns aspectos, de caráter universal, permanecem, mas não todos. O leitor de onze anos no qual Quintana pensou em 1994 será o mesmo leitor de onze anos daqui a vinte ou trinta anos? Ou ainda: o leitor de classe média encontra os mesmos temas que o leitor da periferia? Acreditamos que essa resposta pode ser formulada por diferentes mediadores de leitura que trabalham com diferentes comunidades e/ou grupos de crianças. Segundo Griselda Navas (2000), é preciso pensar sobre quais os aspectos eleitos por uns e outros leitores da mesma faixa etária. Seriam aspectos temáticos ou de ordem formal? O que seria "eleito" ou que aspectos seriam eleitos pelas crianças leitoras de literatura?

Estamos nos adiantando a uma de nossas próximas perguntas: A quem cabe estabelecer os critérios para a escolha de um texto? Parece-nos que cabe ao leitor. Afinal, é ele quem terá uma relação de intimidade com esta (substituir por essa) poesia, o que pode ser algo afetivamente positivo ou não. Por isso, a seleção precisa ser meritória. Em outras palavras, os poemas precisam necessariamente significar. Para que esse relacionamento verdadeiramente se constitua, cabe ao mediador/professor permitir que leitor e poema se encontrem de fato, mesmo que no minuto seguinte o relacionamento se desfaça. É um risco que precisamos correr...

Se cabe ao leitor mirim decidir se quer manter-se junto ou afastado do poema, é preciso permitir o encontro entre texto e leitor. Voltemos ao Sapato florido. Há ali poemas que poderiam ser lidos e compreendidos pelos jovens. É o caso de "Pequenos tormentos da vida".

PEQUENOS TORMENTOS DA VIDA ${ }^{1}$

De cada lado da sala de aula, pelas janelas altas, o azul convida os meninos, as nuvens desenrolam-se, lentas, como quem vai inventando preguiçosamente uma história sem

\footnotetext{
${ }^{1}$. Observe a presença da terceira pessoa do singular: "pensa Margarida". Observe também a inexistência da primeira pessoa do singular.
} 
fim...Sem fim é a sala de aula: e nada acontece, nada...Bocejos e moscas. Se, ao menos, pensa Margarida, se ao menos um avião entrasse por uma janela e saísse pela outra! (QUINTANA, 2005, p. 182)

A temática do poema é por demais atrativa principalmente para o leitor juvenil. Provavelmente, o leitor juvenil tem a maturidade necessária para a reflexão que o poema lhe traz. Esse leitor já pensou muitas vezes sobre o tormento que é a sala de aula, quando seus hormônios lhe indicam o caminho do amor, da rebeldia e da vida. Uma aula monótona nada lhe traz, e ele já sabe disso. Quanto ao leitor infantil, de um modo geral, ainda se encontra apaixonado e envolvido afetivamente por sua professora. Ainda não consegue ser crítico o suficiente para perceber a escola desse modo.

Além da crítica ao regime escolar, o poema traz o elemento mágico, o avião que entra por uma janela e sai pela outra. Com isso, revela que o poema alia a mimesis de um real próximo do leitor ao elemento maravilhoso, tão caro à literatura destinada à infância. Cabe a pergunta: a que leitor se destina esse poema? Se pensarmos na faixa etária, não chegaremos longe, mas, se pensarmos em uma característica psíquica, conseguiremos esboçar um perfil. Trata-se de um leitor ainda preso à magia e ao imaginário característico da infância e que, ao mesmo tempo, já é crítico o suficiente para olhar o mundo ao seu redor. Quintana não incluiu este poema em seu Sapato furado, mas poderia tê-lo feito. Afinal, o poema é perfeito para o público ao qual o poeta destinou seu último livro.

Passemos, agora, ao Pé de pilão, relembrando que o título desta obra se deve à quadrinha popular que o poeta, em sua infância, tanto deve ter ouvido e também repetido: "Pé de pilão/ Carne seca com feijão/Arreda camundongo/ Pra passar o batalhão". (QUINTANA, 1998, p. 7-8):

O pato ganhou sapato,

Foi logo tirar retrato.

O macaco retratista

Era mesmo um grande artista.

Disse ao pato: "Não se mexa

Para depois não ter queixa".

E o pato, duro e sem graça

Como se fosse de massa!

“Olhe pra cá direitinho:

Vai sair um passarinho".

O passarinho saiu,

Bicho assim nunca se viu.

Com três penas no topete

E no rabo apenas sete. 
E como enfeite ele tinha

Um guizo em cada peninha. (QUINTANA, 1998, p. 7-8)

A presença de rimas pode tornar o texto atrativo ao leitor infantil e também chamar sua atenção a tal ponto que lhe passem despercebidos muitos outros aspectos, o que não implica problema algum. Afinal, trata-se de um texto literário, o significa dizer que um leitor perceberá determinado aspecto e outro leitor, com diferentes experiências e bagagem cultural, outro aspecto. Também a presença de animais, como o pato e o macaco, sugere que se trata de um texto destinado ao público infantil. Os guizos, por sua vez, remetem à ludicidade, ao mundo do circo e a um tempo em que havia bobos da Corte; enfim, a um universo infantil e a um mundo distante. Também a ingenuidade de "tirar retrato" porque se conquistou uma roupa nova, no caso, um sapato, e também a antiga frase "Olha o passarinho" - aqui transformada em "Vai sair um passarinho" - remetem a um mundo inicial e aparentemente lúdico. O fato de o passarinho se concretizar e de apresentar características particulares, "três penas no topete/E no rabo apenas sete" (QUINTANA, 1998, p. 2), apenas confirma o universo infantil apresentado no início da obra.

Entretanto, a brincadeira envolvendo o pato, o macaco e o passarinho se transforma em uma discussão e em um aparente conflito que logo é reprimido. Tem-se aí o acréscimo de uma voz e da inserção de novos personagens.

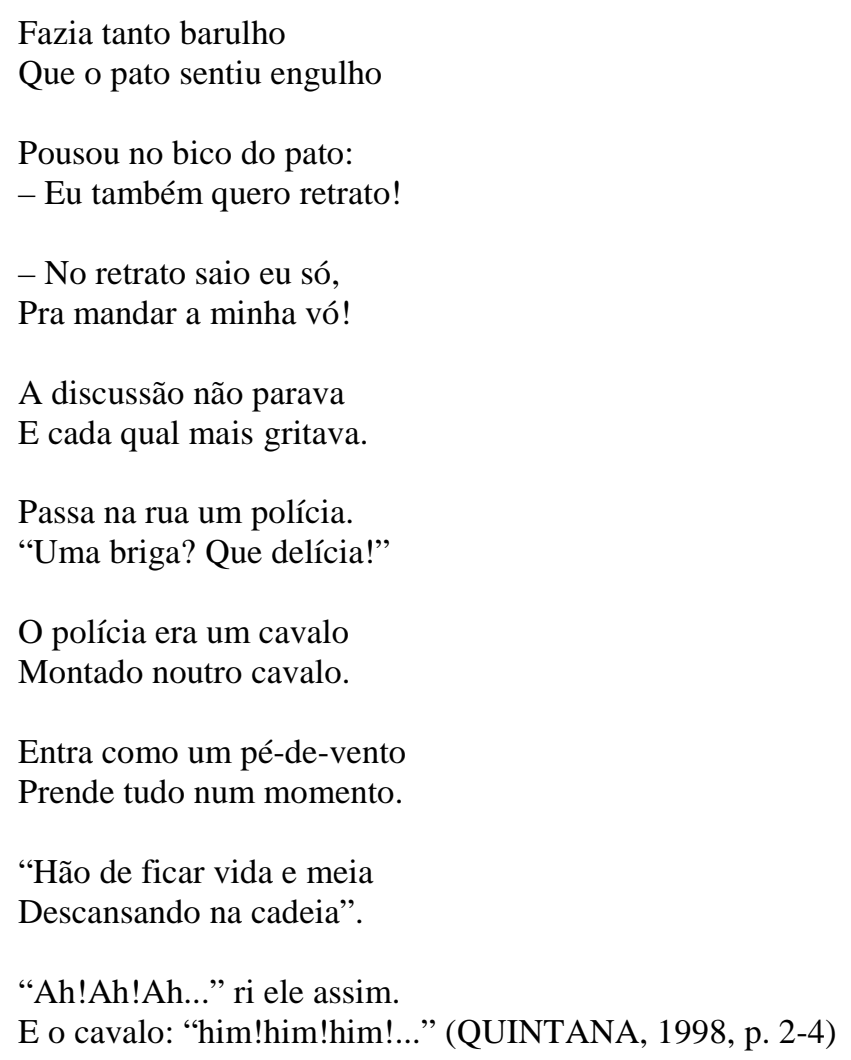

Este segundo excerto revela a briga entre o pato e o passarinho como a briga tola entre crianças que disputam a atenção de um adulto ou a posse de um brinquedo. $\mathrm{O}$ macaco, 
que pouca importância dá à discussão, fica esperando que ela se resolva. No entanto, neste justo momento, aparece a voz da autoridade reinante, a do policial ("Passa na rua um polícia.”). (QUINTANA, 1998, p. 2). O recurso da antropomorfização adquire agora novo significado, uma vez que o policial "era um cavalo/Montado noutro cavalo" (QUINTANA, 1998, p. 4). A ludicidade que o leitor atribuíra ao pato, ao passarinho e ao macaco é deixada de lado. Os significados são revistos e reordenados: a brincadeira que a situação inicial sugeria é reprimida pelo policial. O universo infantil é aniquilado pelo prazer em destruir aquela situação; a voz da autoridade revela o seu prazer em acabar com aquela brincadeira (“Uma briga? Que delícia!”) de forma definitiva ("Hão de ficar vida e meia/Descansando na cadeia”.) (QUINTANA, 1998, p. 2-4).

Por fim, a maldade do policial não condiz com a ludicidade do mundo representado até então. Ocorre aí a primeira quebra de muitas que Mario Quintana utilizou como recurso de construção nesta obra. É importante lembrar que este livro é de 1974, período em que o Brasil ainda sentia as conseqüências da repressão política institucionalizada. Sendo assim, a imagem de um policial animalesco e autoritário não é gratuita.

Na seqüência, há nova quebra com a inserção de personagens até então somente aludidos e que agora são devidamente apresentados:

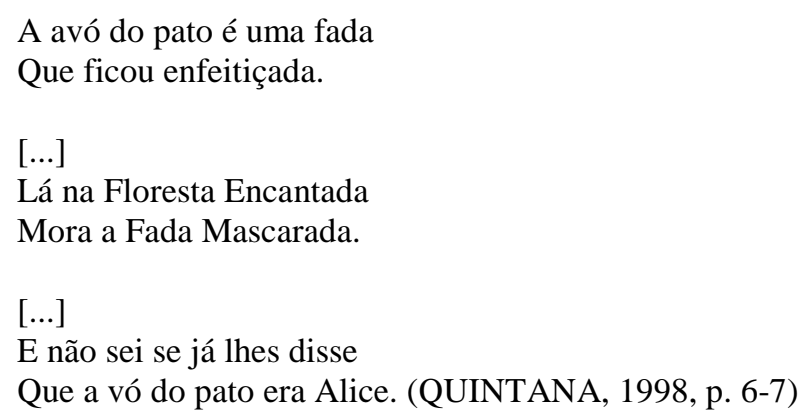

A partir daí, a intertextualidade se faz presente. Fada, Floresta Encantada e Alice remetem a textos que compõem o imaginário da criança e dos adultos. Fada e Floresta Encantada remetem ao universo dos contos de fadas de um modo geral, fazendo-nos entrever Grimm e Perrault principalmente. Quanto à personagem Alice, remete imediatamente às obras de Carrol, em especial a mais conhecida, Alice no país das maravilhas. Ora, temos aí uma grande aventura se delineando. Inicialmente, a atitude do pato, a de tirar retrato com a roupa nova, sugeria a atitude da criança que em geral era levada pelo adulto ao fotógrafo. Aqui é o pato quem toma a atitude, provavelmente, porque se encontrava sozinho no mundo, o que é compreensível a partir dos versos "A avó do pato é uma fada/Que ficou enfeitiçada." [...] E não sei se já lhes disse/ Que a vó do pato era Alice.” (QUINTANA, 1998, p. 8). Enfeitiçada por artes de uma outra Fada, a Fada Mascarada, a ausência da avó do pato se 
explica e permite ler o texto de uma outra forma. Aliás, muitas lacunas devem aqui ser preenchidas pelo leitor, cuja participação passa a ser constantemente exigida.

Em Pé de pilão, a metamorfose é um tema recorrente. Em primeiro lugar, tem-se o pato, que era um menino originalmente: "O pato [...] Era um menino, o Matias." (QUINTANA, 1998, p. 8) Também a avó fora transformada: “Ai, que linda que ela era! E agora seca e amarela." (QUINTANA, 1998, p. 6). A Fada Mascarada, por sua vez, tem o poder da metamorfose: "Conforme lhe dá no gosto,/Cada dia usa um rosto" (QUINTANA, 1998, p.7). Além disso, pode-se dizer que a Alice, de Carrol, não é aqui a mesma personagem; assume novas características físicas (de linda passou a "seca e amarela") e também nova função (é avó do menino/pato). O texto original é uma referência, sendo completamente transformado. As imagens aqui citadas compõem um conjunto ainda maior, o que torna este poema bastante complexo.

Outras características, como o discurso direto, o non sense e a sonoridade, poderiam aproximar o leitor infantil de Pé de pilão. No entanto, o livro infantil também tem muito a dizer ao leitor adulto. $\mathrm{O}$ grau de complexidade encontrado nesta obra pode ser medido pela presença da intertextualidade, pela mimesis da ditadura (nesse sentido, o poeta poderia se associar ao macaco retratista, que, num momento, desenvolvia sua arte e, num segundo momento, tinha seu trabalho cerceado pela censura) e também pela nem tão pequena quantidade de personagens ali presente.

A análise de tais poemas revela diferentes níveis de compreensão da obra de Quintana. Se por um lado há uma possibilidade de encontro entre o poema e o leitor infantil, por outro, também se verifica a possibilidade do encontro entre o texto poético e o leitor adulto, uma vez que as lacunas encontradas nos poemas aqui analisados os tornam altamente complexos.

Respondidas algumas das questões norteadoras aqui formuladas, cabe apontar a importância de continuar esta investigação. Para isso, vê-se a necessidade de analisar outras obras referidas na introdução - O batalhão das letras, Lili inventa o mundo e Sapo amarelo -, a fim de que se tenha clareza quanto à viabilidade de oferecê-las também ao público infantil.

Nesse sentido, o papel do mediador da leitura é fundamental. Cabe a ele a seleção dos poemas a partir critérios anteriormente definidos, levando em conta os interesses do leitor. Tarefa delicada é a de definir a faixa etária a que se destina este ou aquele livro. Entretanto, o conhecimento prévio do livro e o conhecimento prévio do leitor fornecem ao mediador as informações-chave para a tomada da decisão. Além de avaliar a bagagem cultural do leitor e 
sua experiência com a leitura literária, ele tem de definir seu grau de exigência no que se refere ao aprofundamento da leitura. Pode-se perceber tão-somente o aspecto sonoro em Pé de pilão ou tão-somente o aspecto temático em "Pequenos tormentos da vida", deixando de lado outras potencialidades destes poemas. Depende dos objetivos do mediador da leitura.

Por fim, é preciso destacar o caráter plurissignificativo do texto literário. O livro de qualidade para crianças é aquele que também tem muito a dizer para o adulto - e provavelmente não pelos mesmos motivos. É o que se observa na análise de Pé de pilão, de "Pequenos tormentos da vida" e de "Conto azul".

\section{Referências}

NAVAS, Griselda. Niños, lectura y literatura. Caracas (Venezuela): Romor, 2000.

QUINTANA, Mario. Poesia completa. Rio de Janeiro: Nova Aguilar, 2005. Pé de pilão. São Paulo: Ática, 1998. 